\title{
Design of Composite Disc Spring for Automotive Suspension with using Nume- rical Simulation
}

Martin Mrazek, Michal Skovajsa, Frantisek Sedlacek (0000-0003-1678-149X)

Faculty of Mechanical Engineering, University of West Bohemia in Pilsen. Univerzitni 8, 30001 Plzen. Czech

Republic. E-mail:mrma@kks.zcu.cz, skovi@kks.zcu.cz, fsedlace@kks.zcu.cz

This paper investigates the replacement of a conventional steel coil spring with a composite disc spring with the aim of minimizing its weight. Simulation in the CAD system Siemens NX 12 was used to determine the composite disc spring's behavior. The regression functions were stated based on the numerical simulation. Based on the regression functions the solution with the minimum weight was found using software programmed in Matlab. The prototype discs were manufactured from carbon fibre prepreg. Their load-deflection characteristics were tested and compared with the designed values. The experimental results show that using this solution reduces the weight by about $30 \%$ in this case.

Keywords: carbon fibre, composite material, disc spring, optimization

\section{Introduction}

There is a Europe-wide trend to reduce $\mathrm{CO} 2$ emissions in road vehicles. One of the ways to reduce $\mathrm{CO} 2$ emissions is to make a vehicle lighter. Coil springs are used in many automotive applications. They are made of steel and have a high total weight. Coil springs are often dynamically loaded and if they are made from steel there is no way to reduce the weight much.

Many authors [7][8][9] investigate mathematical modelling of composites disc springs and the theoretical application. There is no study of replacing conventional steel coil springs with composites disc springs focused to weight in the real situation. The manufacture process of disc spring is relatively simple it could be manufactured in prototype production with acceptable cost. Additionally, disc springs allow a large range of non-linear load-deflection curves and spring rates to be achieved. This is done by stacking of disc springs in series and parallel, offering further means to obtain desired stiffness variation [7].

This paper investigates the possibility of replacing the steel coil spring with carbon fibre composite disc springs to minimize weight. The damper with steel coil spring (ZF Formula Student) was chosen for this case study.

\section{Case study}

The coil spring of the damper is made from EN 10270-1 steel with linear load-deflection curve. The damper with the spring is shown in Fig. 1. The weight of one spring is $0.372 \mathrm{~kg}$. The spring must provide a minimum compression of $35 \mathrm{~mm}$. It is depended on suspension kinematic and the rules where the minimum wheel travel is defined [1]. The limitation factor for the design of the new damper is the space where the spring can be placed. The maximum outer diameter is $70 \mathrm{~mm}$, the minimum inner diameter is $42 \mathrm{~mm}$ and the maximum height is $147 \mathrm{~mm}$.

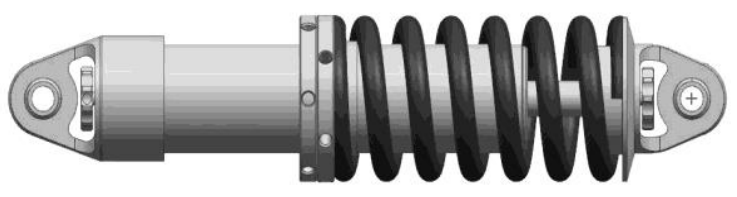

Fig. 1 Damper with the coil spring

A typical disc spring geometric parameters is shown in Fig.2. The Load-deflection curve is typically non-linear dependent to $h_{0} / t$ ratio. For $h_{0} / t$ ratio 0.4 , 0.8 and 1.2 the load-deflection is approximately linear, medium regression, and high regression [11].

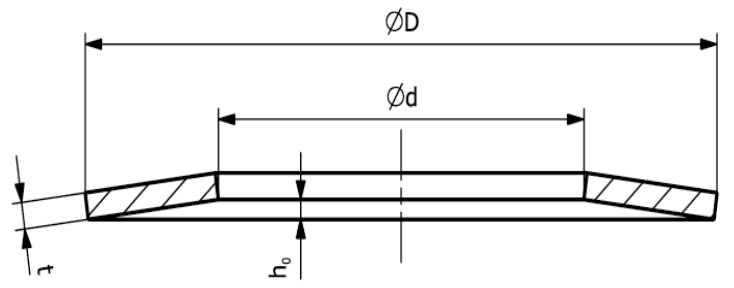

Fig. 2 Geometrical parameters of typical disc spring

\section{Design of composite disk spring}

Because a plate spring has low maximum compression, several disks in series are needed. Standard disc springs in a serial arrangement need a tube or a shaft to hold all the discs centred. We designed a flange on each disc to eliminate the need for this (Fig. 3). 

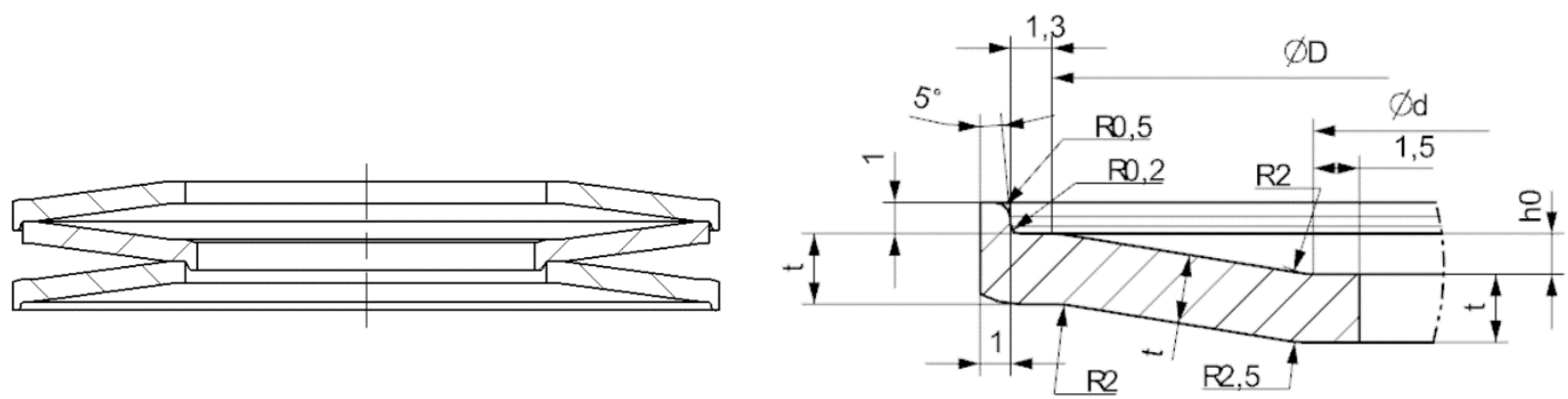

Fig. 3 The serial arrangement of discs (left); Disc with outer flange - basic dimensions (right)

If we want to make a spring from steel or other isotropic materials, we use basic relations to calculate them. Be-cause composite materials do not exhibit isotropic behaviour, these basic relations cannot be used. Numerical simulation based on FEM and software developed in Matlab were used for finding the basic dimensions of the springs and number of the discs. The spring behavior was described by regression functions. FEM analysis was used to determine the regression coefficients and Matlab software to search for a low-weight solution which corresponds to the

\section{CQUAD8}

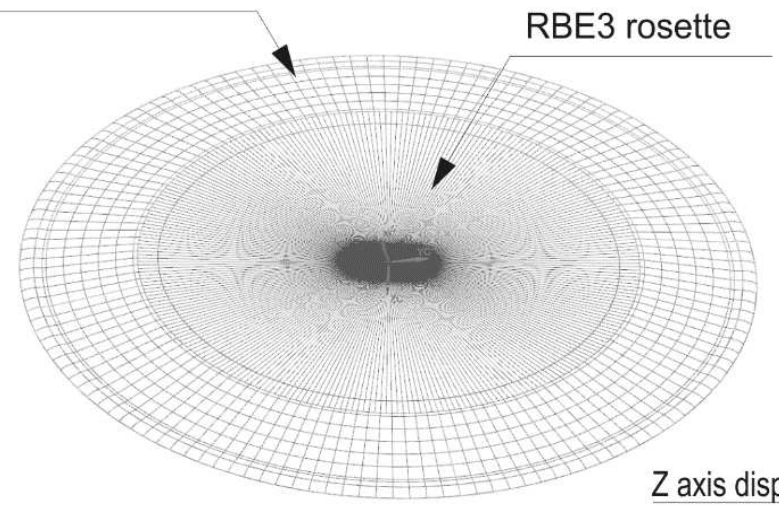

$Z$ axis displacement fixed defined conditions [13].

FEM analysis was performed on a disc which has a flange on the outer diameter side. On the model surface was applied mesh with a second order quadratic elements (type CQUAD8) [3]. The centre point of the disc and the inner edge was connected by a $1 \mathrm{D}$ connection (RBE3 elements). Fig. 4 shows the boundary conditions which were applied on the outer edge and the centre point. The load was applied to the centre point as a z-direction displacement.

\section{Load ( $Z$ direction}

displacement) applied

$\mathrm{X}, \mathrm{Y}$ axis displacement fixed

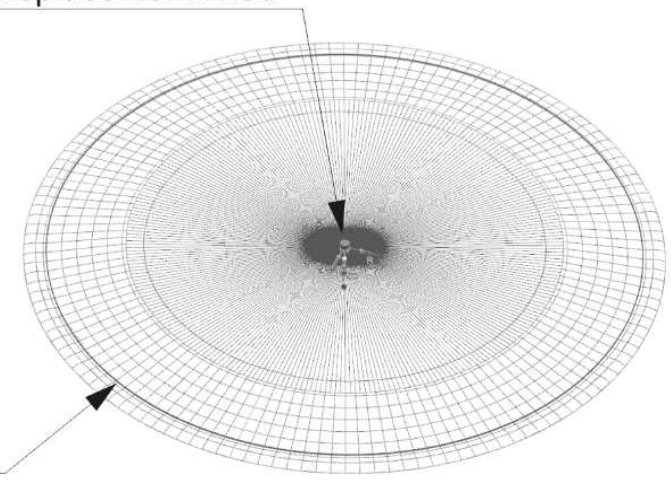

Fig. 4 Specimen of mesh (left); Boundary conditions (right)

Tab. 1 Carbon fibre prepreg GG200t mechanical properties

\begin{tabular}{|l|c|l|l|}
\hline $\mathrm{t}(\mathrm{mm})$ & 0.203 & Thickness of the ply & \\
\hline $\mathrm{\varrho}\left(\mathrm{kg} / \mathrm{m}^{3}\right)$ & 1570 & Density & \\
\hline $\mathrm{E}_{1}(\mathrm{GPa})$ & 55.8 & Young's Modulus $0^{\circ}$ & $\begin{array}{l}\text { acc. to ASTM D } \\
3039\end{array}$ \\
\hline $\mathrm{E}_{2}(\mathrm{GPa})$ & 53.7 & Young's Modulus $90^{\circ}$ & $\begin{array}{l}\text { acc. to ASTM D } \\
3039\end{array}$ \\
\hline $\mathrm{E}_{3}(\mathrm{GPa})$ & 6.4 & Young's Modulus N90 & $\begin{array}{l}\text { acc. to ASTM D } \\
3039\end{array}$ \\
\hline $\mathrm{G}_{12}(\mathrm{GPa})$ & 5.29 & In-plane Shear Modulus & $\begin{array}{l}\text { acc. to ASTM D } \\
3518\end{array}$ \\
\hline$\nu_{12}(-)$ & 0.27 & Major Poisson's Ratio & $\begin{array}{l}\text { acc. to ASTM D } \\
3039\end{array}$ \\
\hline
\end{tabular}


The carbon fibre prepreg GG200t - twill 2x2 with epoxy matrix was used [12]. The mechanical properties used material for numeric simulation are given in Tab. 1.

The maximum stress failure criterion was used to evaluate the strength of the spring. According to this theory, failure occurs when any stress component reaches the ultimate strength of the material [2]. The maximum stress criterion and maximum strength values are shown in Tab. 2.

Tab. 2Maximum stress criterion (left); Maximum strength value for carbon fibre GG200t

\begin{tabular}{|c|c|c|c|c|}
\hline $\begin{array}{c}\text { Failure inde- } \\
\text { xes } \\
\end{array}$ & Maximum stress criterion & $\begin{array}{c}\mathrm{X}^{\mathrm{T}} \\
(\mathrm{MPa}) \\
\end{array}$ & 693 & Tensile strength $\left(0^{\circ}\right)$ \\
\hline $\mathrm{F}_{11}$ & $\sigma_{1} / \mathrm{X}^{\mathrm{T}}$ if $\sigma_{1}>0 ; \sigma_{1} / \mathrm{X}^{\mathrm{C}}$ if $\sigma_{1}<0$ & $\begin{array}{c}\mathrm{Y}^{\mathrm{T}} \\
(\mathrm{MPa})\end{array}$ & 610 & Tensile strength $\left(90^{\circ}\right)$ \\
\hline $\mathrm{F}_{22}$ & $\sigma_{2} / Y^{\mathrm{T}}$ if $\sigma_{2}>0 ; \sigma_{2} / Y^{\mathrm{C}}$ if $\sigma_{2}<0$ & $\begin{array}{c}Z^{\mathrm{T}} \\
(\mathrm{MPa}) \\
\end{array}$ & 67 & Tensile strength $\left(\mathrm{N} 90^{\circ}\right)$ \\
\hline $\mathrm{F}_{33}$ & $\sigma_{3} / Z^{\mathrm{T}}$ if $\sigma_{3}>0 ; \sigma_{3} / Z^{\mathrm{C}}$ if $\sigma_{3}<0$ & $\begin{array}{c}\mathrm{X}^{\mathrm{C}} \\
(\mathrm{MPa})\end{array}$ & 552 & Compression strength $\left(0^{\circ}\right)$ \\
\hline $\mathrm{F}_{12}$ & $\left|\tau_{12} / S_{12}\right|$ & $\begin{array}{c}\mathrm{Y}^{\mathrm{C}} \\
(\mathrm{MPa})\end{array}$ & 558 & Compression strength $\left(90^{\circ}\right)$ \\
\hline $\mathrm{F}_{23}$ & $\left|\tau_{23} / S_{23}\right|$ & $\begin{array}{c}\mathrm{Z}^{\mathrm{C}} \\
(\mathrm{MPa})\end{array}$ & 268 & $\begin{array}{l}\text { Compression strength } \\
\left(\mathrm{N} 90^{\circ}\right)\end{array}$ \\
\hline $\mathrm{F}_{13}$ & $\left|\tau_{13} / S_{13}\right|$ & $\begin{array}{c}\mathrm{S}_{12} \\
(\mathrm{MPa}) \\
\end{array}$ & 109.1 & In-Plane Shear Strength \\
\hline $\mathrm{F}_{\mathrm{IL}}$ & $\sqrt{\left(\frac{\tau_{13}}{S_{13}}\right)^{2}+\left(\frac{\tau_{23}}{S_{23}}\right)^{2}}$ & $\begin{array}{l}\text { S }_{\text {ILSS }} \\
(\mathrm{MPa})\end{array}$ & 67.7 & In-Lam. Shear Strength \\
\hline
\end{tabular}

Tab. 3 shows the dimensions of the discs and calculated values that were necessary for the regression function. The inner diameter $\boldsymbol{d}$ was constant $48 \mathrm{~mm}$, the outer diameter $\boldsymbol{D}$ was expected in the range
$60-70 \mathrm{~mm}$, the height-thickness ratio $\boldsymbol{h}_{\boldsymbol{0}} / \boldsymbol{t}$ was expected in the range $0.5-0.8$, the thickness was expected from $1,5 \mathrm{~mm}$ to $3 \mathrm{~mm}$, the maximum deflection was expected from $60 \%$ to $95 \%$.

Tab. 3 Dimensions of the disc and calculated values

\begin{tabular}{|c|c|c|c|c|c|c|}
\hline $\mathrm{d}$ & $\mathrm{D}$ & $\mathrm{h}_{0} / \mathrm{t}$ & $\mathrm{t}$ & $\mathrm{S}_{\mathrm{p}}$ & $\mathrm{F}_{\mathrm{z}}$ & $\mathrm{F}_{\mathrm{I}}$ \\
\hline$[\mathrm{mm}]$ & {$[\mathrm{mm}]$} & {$[-]$} & {$[\mathrm{mm}]$} & {$[\%]$} & {$[\mathrm{N}]$} & {$[-]$} \\
\hline 48 & 70 & 0.5 & 1.5 & 60 & 201 & 0.155 \\
\hline 48 & 70 & 0.5 & 1.5 & 95 & 318 & 0.247 \\
\hline 48 & 70 & 0.5 & 3 & 60 & 2990 & 0.592 \\
\hline 48 & 70 & 0.5 & 3 & 95 & 4736 & 0.937 \\
\hline 48 & 70 & 0.8 & 1.5 & 60 & 435 & 0.298 \\
\hline 48 & 70 & 0.8 & 1.5 & 95 & 689 & 0.47 \\
\hline 48 & 70 & 0.8 & 3 & 60 & 6311 & 1.129 \\
\hline 48 & 70 & 0.8 & 3 & 95 & 9993 & 1.787 \\
\hline 48 & 60 & 0.5 & 1.5 & 60 & 460 & 0.268 \\
\hline 48 & 60 & 0.5 & 1.5 & 95 & 729 & 0.425 \\
\hline 48 & 60 & 0.5 & 3 & 60 & 6332 & 0.98 \\
\hline 48 & 60 & 0.5 & 3 & 95 & 10026 & 1.558 \\
\hline 48 & 60 & 0.8 & 1.5 & 60 & 1027 & 0.516 \\
\hline 48 & 60 & 0.8 & 1.5 & 95 & 1626 & 0.817 \\
\hline 48 & 60 & 0.8 & 3 & 60 & 8281 & 1.235 \\
\hline 48 & 60 & 0.8 & 3 & 95 & 13112 & 1.955 \\
\hline
\end{tabular}


The general form of the regression function for reaction force is

$$
F_{Z}=b_{0} \cdot\left(\frac{h_{0}}{t}\right)^{b_{1}} \cdot t^{b_{2}} \cdot s_{p} b_{3} \cdot D^{b_{4}}
$$

and the general form of the regression function for failure index calculation is

$$
F_{I}=c_{0} \cdot\left(\frac{h_{0}}{t}\right)^{c_{1}} \cdot t^{c_{2}} \cdot s_{p}{ }^{c_{3}} \cdot D^{c_{4}},
$$

and the regression constants were calculated based on Tab. 3. The final formulas are

$$
\begin{aligned}
& F_{Z}=240507 \cdot\left(\frac{h_{0}}{t}\right)^{0.868037} \cdot t^{3.39526} \cdot s_{p}^{1.00014} \cdot D^{-2.67542} \\
& F_{I}=3.17252 \cdot\left(\frac{h_{0}}{t}\right)^{0.861713} \cdot t^{1.61125} \cdot s_{p}^{1.00126} \cdot D^{-1.59992}
\end{aligned}
$$

The regression constants show that the reaction force and failure index have almost linear dependence on the disc compression. The reaction force is mostly dependent on the disc thickness. The failure index has a negative dependency on the outer disc diameter.

Tab. 4 Matlab boundary conditions

\begin{tabular}{|l|l|l|}
\hline Parameter & Condition & Description \\
\hline$m[\mathrm{~kg}]$ & min & Weight \\
\hline$F_{I}[-]$ & $<0.9$ & Failure index \\
\hline$k[\mathrm{~N} \mathrm{~mm}-1]$ & $80-90$ & Stiffness \\
\hline$d[\mathrm{~mm}]$ & 48 & Inner diameter \\
\hline$s[\mathrm{~mm}]$ & $s<h_{0}$ & Deflection \\
\hline$n[-]$ & $6-40$ & Number of disc for one damper \\
\hline$t[\mathrm{~mm}]$ & $1-3.0$ & Disc thickness \\
\hline$s t[\mathrm{~mm}]$ & 35 & Damper compression \\
\hline
\end{tabular}

When the mathematical equation and the boundary conditions have been determined (Tab. 4) the final spring parameters can be calculated. The software in Matlab is used. The software calculates the dimensions and number of discs for one damper. The values which correspond to the boundary conditions are sorted by weight (Tab. 5).

Tab. 5 Matlab calculation result

\begin{tabular}{|l|l|l|l|l|l|l|}
\hline $\begin{array}{l}m \\
{[\mathrm{~kg}]}\end{array}$ & $\begin{array}{l}F_{I} \\
{[-]}\end{array}$ & $\begin{array}{l}k \\
{\left[\mathrm{~N} \mathrm{~mm}^{-1}\right]}\end{array}$ & $\begin{array}{l}n \\
{[-]}\end{array}$ & $\begin{array}{l}D \\
{[\mathrm{~mm}]}\end{array}$ & $\begin{array}{l}h_{0} \\
{[\mathrm{~mm}]}\end{array}$ & $\begin{array}{l}t \\
{[\mathrm{~mm}]}\end{array}$ \\
\hline 0.273 & 0.87 & 79.1 & 32 & 64 & 1.21 & 2.2 \\
\hline 0.273 & 0.87 & 79.0 & 32 & 64 & 1.23 & 2.2 \\
\hline 0.273 & 0.86 & 78.8 & 32 & 64 & 1.25 & 2.2 \\
\hline 0.273 & 0.86 & 78.6 & 32 & 64 & 1.28 & 2.2 \\
\hline 0.273 & 0.86 & 78.4 & 32 & 64 & 1.30 & 2.2 \\
\hline 0.273 & 0.86 & 78.2 & 32 & 64 & 1.32 & 2.2 \\
\hline
\end{tabular}

\section{Experimental testing}

One pair of discs was manufactured based on the calculated data. The discs were both laminated in one mould specially designed for this experiment [5][6]. The mould was built in two parts from aluminium alloy. This solution provides high surface quality on both sides of the laminated part [4]. The laminate layup was $[0 / 45]_{6}$. The springs were cured in an autoclave with an external pressure of 2 bars and a temperature of $110^{\circ} \mathrm{C}$. The final manufactured discs are shown in Fig. 5.

Both discs were compression tested to check their load-deflection behaviour. Fig. 6 and Fig. 7 shows the typical set-up for testing on the electro-mechanical testing machine Zwick/Roell Z250 . A compression test speed of $1 \mathrm{~mm} / \mathrm{min}$ was used with a compression limit of $1.5 \mathrm{~mm}$. Each disc was tested separately.

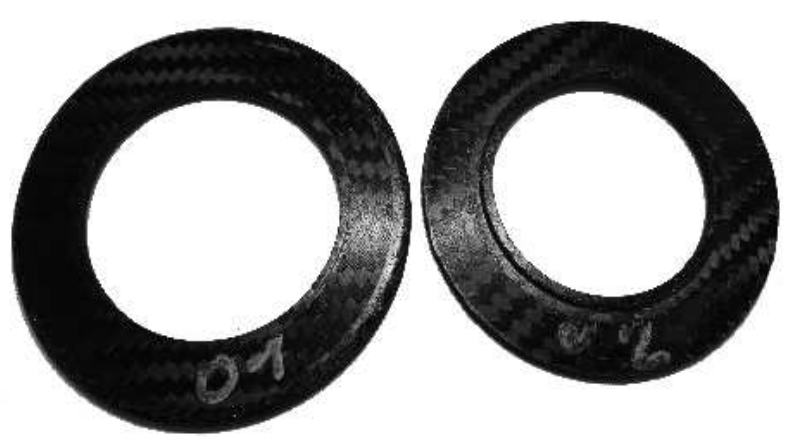

Fig. 5 Samples of manufactured springs 


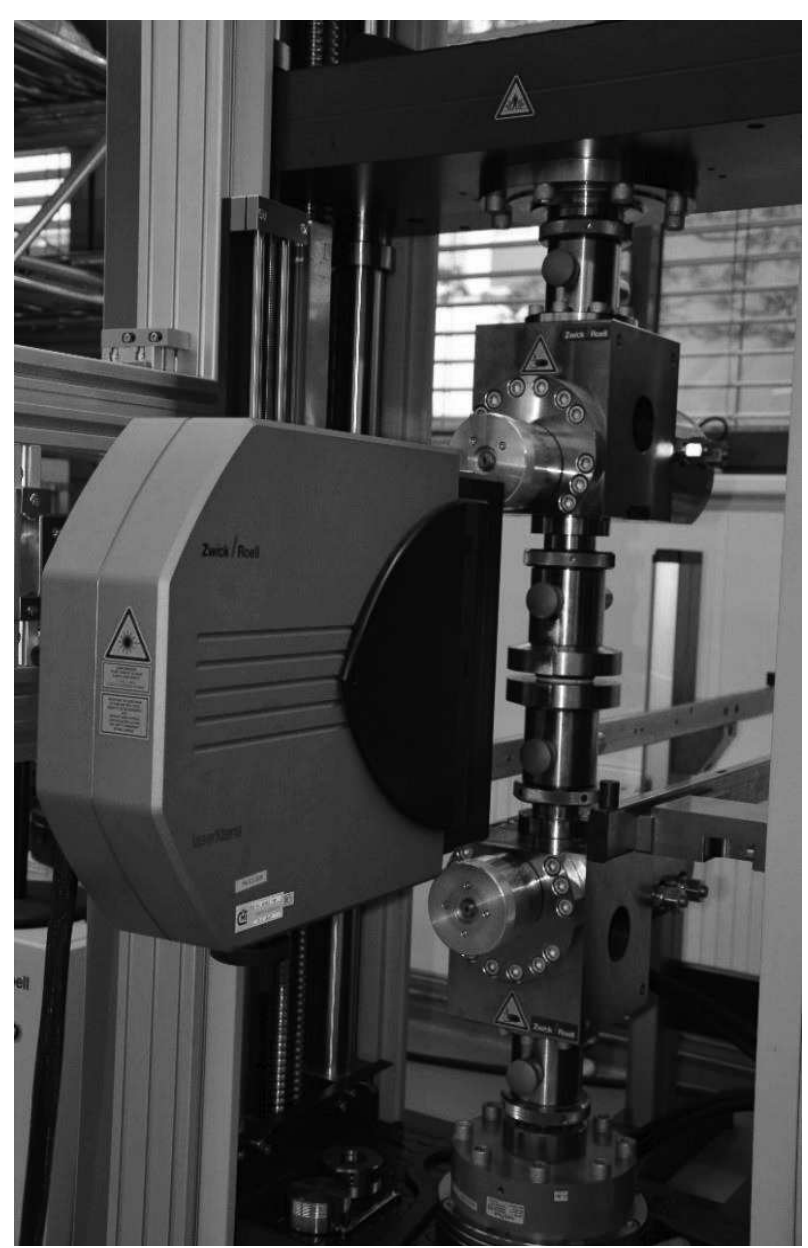

Fig. 6 Load-deflection testing

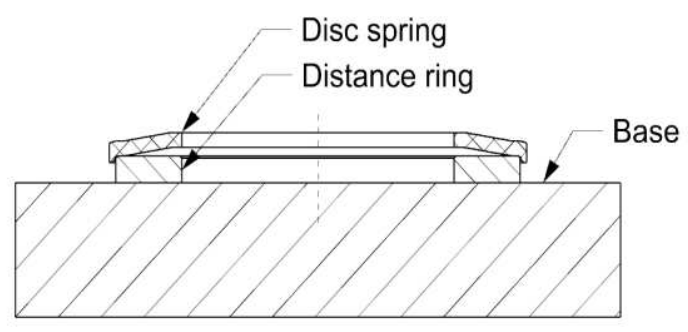

Fig. 7 Typical testing setup

The weight was measured using an analytical laboratory scale with an accuracy of $0.001 \mathrm{~g}$.

The thickness was measured with a micrometre with an accuracy of $0.01 \mathrm{~mm}$. Three points on each disc were measured.

\section{Tab. 6 Discs weight}

\begin{tabular}{|l|c|c|}
\hline & $\begin{array}{c}\text { Thic- } \\
\text { kness } \\
{[\mathrm{mm}]}\end{array}$ & $\begin{array}{c}\text { Weight } \\
\text { [g] }\end{array}$ \\
\hline Disc with outer flange & 2.247 & 8.585 \\
\hline Disc with inner flange & 2.257 & 7.947 \\
\hline
\end{tabular}

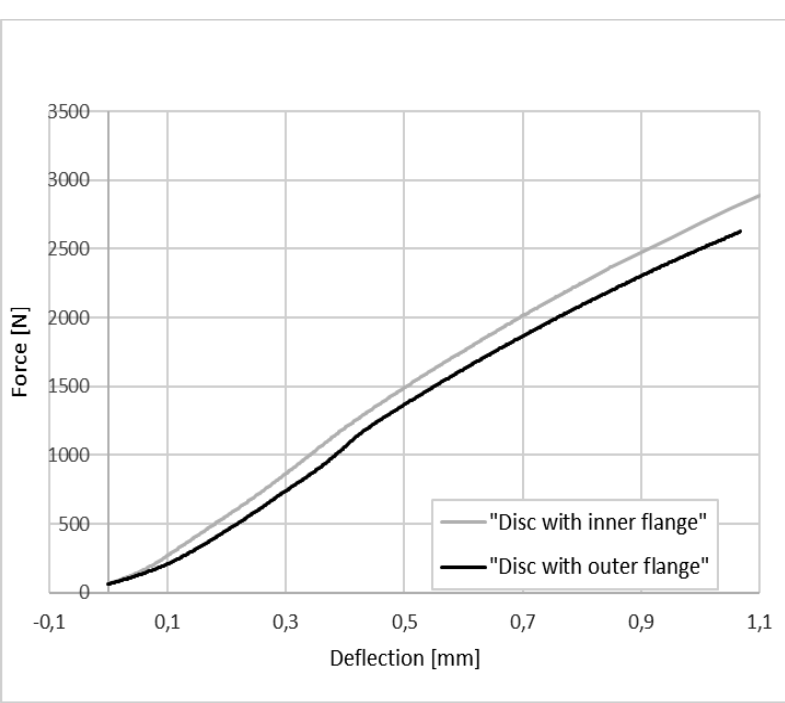

Fig. 8 Load-deflection characteristic

\begin{tabular}{r|c|c|c|c|c} 
No. & Specimen ID & $E_{\bmod }$ & $F_{\max }$ & dL at $F_{\max }$ & Notes \\
$\mathrm{N} / \mathrm{mm}$ & $\mathrm{N}$ & $\mathrm{mm}$ & \\
\hline 1 & $01+$ extens. & 2850 & 2630 & 1,1 & $\mathrm{E}(300-2000 \mathrm{~N})$ \\
\hline 2 & $01+$ extens. & 2850 & 2620 & 1,1 & $\mathrm{E}(300-2000 \mathrm{~N})$ \\
\hline 3 & $02+$ extens. & 2980 & 2890 & 1,1 & $\mathrm{E}(300-2000 \mathrm{~N})$ \\
\hline 4 & $02+$ extens. & 2980 & 2870 & 1,1 & $\mathrm{E}(300-2000 \mathrm{~N})$ \\
\hline
\end{tabular}

Fig. 9 Load-deflection test results

\section{Results from experimental testing and discussion}

One pair of disc springs was manufactured. Tab. 6 shows the thickness of each disc. The differences between the calculated and measured thickness is about $2.5 \%$. The weight measurement shows differences between the discs. This difference is caused by the geometrical differences between the discs. The weight of all the discs needed for the damper is $265 \mathrm{~g}$. This is $107 \mathrm{~g}(29 \%)$ less than the original steel spring. If we compare this weight with the calculated value, the differences can be seen. This is due to the simplification of the calculation. In the calculation, only the spring with the outer flange was used.

Fig. 8 shows the load-deflection characteristics of the disc. The nonlinearity from the whole range was evaluated. The non-linearity of the disc with the inner flange is $2.6 \%$. The non-linearity of the disc with the outer flange is $8.7 \%$. If we calculate stiffness from maximum displacement and maximum load and divide the value by the number of discs needed for the damper, this is the same way as the calculation software did the stiffness calculation. The stiffness of the disc with the outer flange is $75 \mathrm{~N} / \mathrm{mm}$. The stiffness of the disc with the inner flange is $82 \mathrm{~N} / \mathrm{mm}$. The comparison of the designed stiffness (Tab. 5) and the measured stiffness is $5.5 \%$ for the disc with the outer flange and $3.5 \%$ for the disc with the inner flange. The design process shows the Fig. 10. 


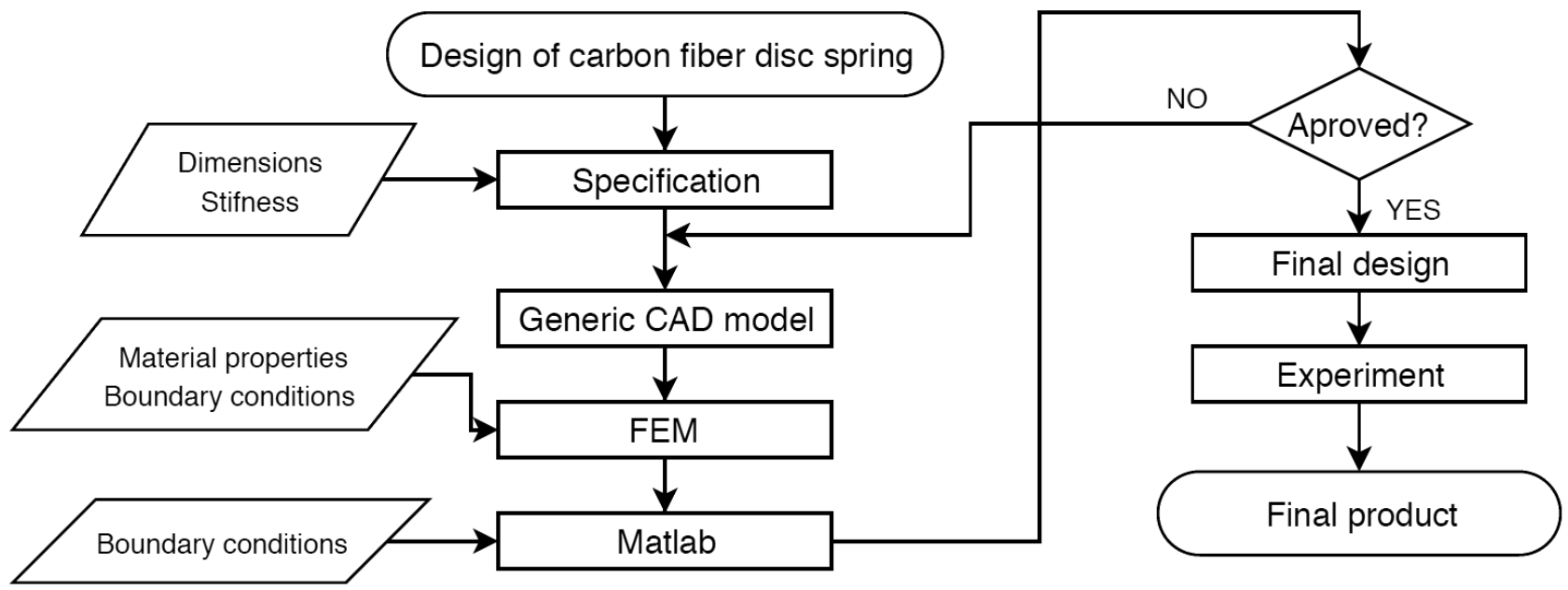

Fig. 10 Design process flowchart

\section{Conclusion}

This paper deals with the possibility of replacing the steel coil spring with carbon fibre composite disc springs to minimize weight. The carbon fibre disc springs were designed using FEA and Matlab software. One pair of discs was manufactured and experimentally tested. Comparison of the designed parameters and experimental testing results found a difference in stiffness of $5.5 \%$ and $3.5 \%$. The designed solution is $29 \%$ lighter than the original coil spring. The designed solution shows the possibility of replacing the steel coil spring with the carbon fibre composite disc spring in this case.

\section{Acknowledgement}

The article has been prepared under project SGS2019-030 - Research and development of Advanced Components for the Formula Student Car.

\section{References}

[1] Formula student FSG RULES 2020. Online. 5.1.2020. www.fsg.one/rules

[2] VASILIEV, VALERY V A MOROZOV, EVGENY V (2013). Advanced Mechanics of Composite Materials and Structural elements, 3rd Edition. Oxford: Elsevier, 2013. ISBN: 978-0-08098231-1.

[3] O. C. ZIENKIEWICZ, R. L. TAYLOR, AND J. Z. ZHU (2013). The Finite Element Method: Its Basis and Fundamentals, Seventh Edition, 7 edition. Amsterdam: Butterworth-Heinemann, 2013.

[4] A. C. LONG, ED. (2005). Design and Manufacture of Textile Composites, 1 edition. Boca Raton, Fla.: Woodhead Publishing, 2005.
[5] HYNEK, M.., ŘEHOUNEK, L, VOTÁPEK, P. (2013).. Numerical analysis of production procedure of alluminium bellows by means of hydroforming. In Metal 2013. Ostrava: Tanger, 2013. s. 496-501. ISBN: 978-80-87294-39-0

[6] RUSNAKOVA S, CAPKA A, FOJTL L, ZALUDEK M, RUSNAK V. (2016). Technology and Mold Design for Production of Hollow Carbon Composite Parts. Manufacturing Technology. 2016;16(4):799-804. doi: 10.21062/ujep/x.2016/a/12132489/MT/16/4/799.

[7] FOARD, J., ROLLASON, D., THITE, A., \& BELL, C. (2019). Polymer composite Belleville springs for an automotive application. Composite Structures, 221, 110891. https://doi.org/10.1016/j.compstruct.2019.04 .063

[8] ZHENG, E., JIA, F., \& ZHOU, X. (2014). Energy-based method for nonlinear characteristics analysis of Belleville springs. Thin-Walled Structures, 79, 52-61. https://doi.org/10.1016/j.tws.2014.01.025

[9] PATANGTALO, W., AIMMANEE, S., \& CHUTIMA, S. (2016). A unified analysis of isotropic and composite Belleville springs. ThinWalled Structures, 109, 285-295. https://doi.org/10.1016/j.tws.2016.09.023

[10] JOSH WINKLER. (2018). Composite Spring Capabilities, 2018. URL: https://wnw.mwind.com/composite-spring-capabilities/.

[11] WANG, W., WANG, X. (2020). Tests, model, and applications for coned-disc-spring vertical isolation bearings. Bull Earthquake Eng 18, 357- 
398 (2020). https://doi.org/10.1007/s10518019-00728-8

[12] MAŇAS L, RUSNÁKOVÁ S, JAVOŘÍK J, ŽALUDEK M, FOJTL L. (2019). Verification of Material Composition and Manufacturing Process of Carbon Fibre Wheel. Manufacturing Technology. 2019;19(2):280-283. doi: 10.21062/ujep/283.2019/a/12132489/MT/19/2/280.
[13] KULHAVÝ P, FLIEGEL V. (2019). Experimental and Numerical Analysis of Dynamic Properties of Wound and Wrapped Carbon Composites. Manufacturing Technology. 2019;19(2):248-253.

doi:

2489/MT/19/2/248. 